\title{
Economic impact of digestive, nutritional and oral diseases in Canada
}

\author{
Richard N Fedorak MD \\ President, Canadian Association of Gastroenterology
}

$I^{n}$ n preparing the 2000 Canadian Institute for Health Research in Digestive, Nutritional and Oral Health Sciences Application, it was necessary to identify the economic impact of these disorders on Canadians and the Canadian Economy. Below are several excerpts from the application that highlight the significant economic impact of digestive, nutritional and oral dental disorders. I am indebted to Dr Ivan Beck, Queens University, Kingston, Ontario for his diligence in assimilating this information.

\section{OVERALL DIRECT ECONOMIC BURDEN}

Digestive and nutritional diseases, which include disorders of the mouth, esophagus, stomach, small and large intestines, liver and pancreas, are a major health problem in Canada. They have been recognized as a first order economic burden to Canadian health care since the early 1960s (1) (Table 1).

In 1997, Moore et al (2), using Canadian data, determined that the actual cost of the combination of digestive, nutritional and oral diseases is $\$ 8.67$ billion (18\% of the total health care economic burden of Canada). This makes the digestive, nutritional and oral diseases the highest health care economic burden of all disease in Canada. In contrast, the direct cost of cardiovascular diseases is $\$ 7.35$ billion, mental disorders $\$ 5$ billion and respiratory diseases $\$ 3.78$ billion (Figure 1 ).

\section{INPATIENT ACTIVITY}

Inpatient hospital separations for the fiscal year 1996/97 indicate that there were 402,460 hospital discharges with a primary diagnosis of digestive disease (excluding neoplasms). This number was second only to that of cardiovascular system diseases, with 462,035 discharges. Furthermore, inpatient separations for digestive conditions were greater than for respiratory diseases $(320,427)$, mental diseases $(173,785)$ and diseases of the nervous system and sensory organs (central nervous system) $(6,604)$ (Figure 2).

\section{OUTPATIENT ACTIVITY}

It is more difficult to obtain accurate retrospective outpatient data because the majority of provinces do not require an accurate diagnosis for payment of physician fees. The most accessible, although incomplete, outpatient data can be assessed using information provided by drug care programs. These pro-

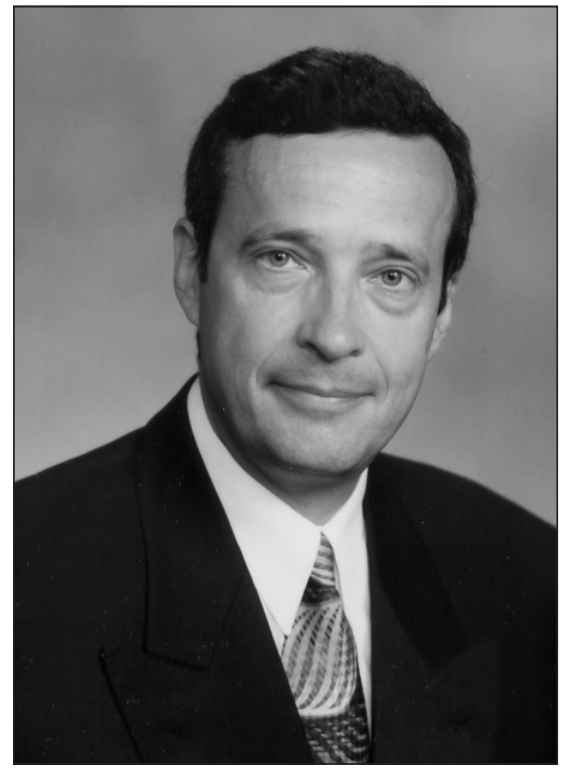

grams are only comprehensive for persons who are 65 years of age or older. Furthermore, these data, except in unusual circumstances, do not include over-the-counter drugs such as antacids, laxatives or antidiarrheal agents. In spite of these shortcomings, provincial drug utilization data may provide a reasonable assessment of the magnitude of outpatient use. The Ontario Drug Benefit Program data indicate that, in 1998, the total drug expenses for all conditions were $\$ 1.643$ billion, expenses for nutrients were $\$ 17.0$ million and drug expenses for digestive disease were $\$ 212.1$ million. In Ontario, therefore, nutrients and gastrointestinal drugs together constituted 14\% of total use of drugs. Thus, 1998 outpatient statistics do not really differ from findings in which the economic burden of the entire burden of digestive, nutritional and dental disease in Canada was $14.6 \%$ in 1961, 15.3\% in 1971 and 18\% in 1993 (Table 1).

However, because provincial drug programs do not cover over-the-counter medications, the true outpatient costs due to mild, gastrointestinal diseases cannot be evaluated by these methods. 
TABLE 1

Rank of total direct physician and hospital costs in Canada and the United States

\begin{tabular}{lccc}
\hline & & Rank & \\
& Canada & Canada & United States \\
& $\mathbf{1 9 6 1}$ & $\mathbf{1 9 7 1}$ & $\mathbf{1 9 6 3}$ \\
\hline Digestive & 2 & 1 & 1 \\
Genitourinary & 2 & 1 & 1 \\
Mental & 1 & 2 & 2 \\
Cardiovascular & 5 & 3 & 3 \\
Accidents & 7 & 4 & 4 \\
Respiratory & 3 & 5 & 5 \\
Neoplasms & 9 & 6 & 8 \\
Central nervous system & 10 & 8 & 6 \\
Other & 12 & 9 & 11 \\
Obstetrical & 4 & 10 & 7 \\
Musculoskeletal & 11 & 11 & 10 \\
III-defined & 14 & 12 & 13 \\
Endocrine & 15 & 13 & 12 \\
Infective & 6 & 14 & 14 \\
Skin & 13 & 15 & 15 \\
Congenital & 17 & 16 & 17 \\
Blood & 18 & 17 & 16 \\
Perinatal & 16 & 18 & 18 \\
\hline
\end{tabular}

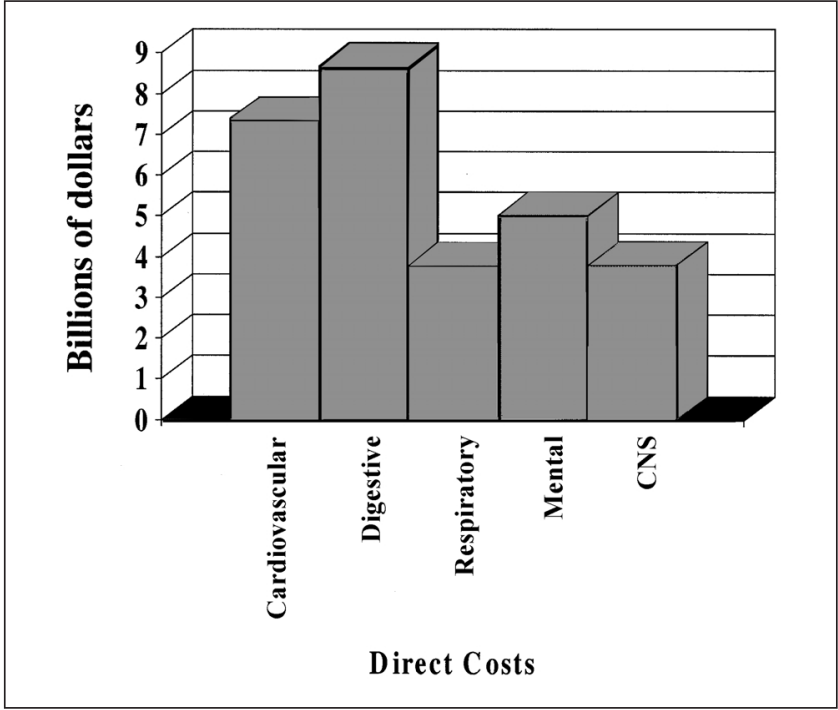

Figure 1) Direct cost, in billions of dollars, for digestive, nutritional and oral health care in Canada during 1997. The economic impact of digestive, nutritional and oral health care ranks first in Canada overall, and represents billions of dollars (18\% of the total health care economic burden of Canada). Digestive includes gastrointestinal, nutritional and oral health. CNS Central nervous system. Data from reference 1

\section{INDIRECT ECONOMIC BURDEN}

The impact of chronic upper gastrointestinal complaints on absenteeism and productivity is substantial. Persons with gastrointestinal symptoms missed nine times as many workdays due to gastrointestinal symptoms as did people without symptoms. Loss of work for digestive diseases costs Canadians $\$ 1.14$ billion and is in fourth place immediately after respiratory dis-

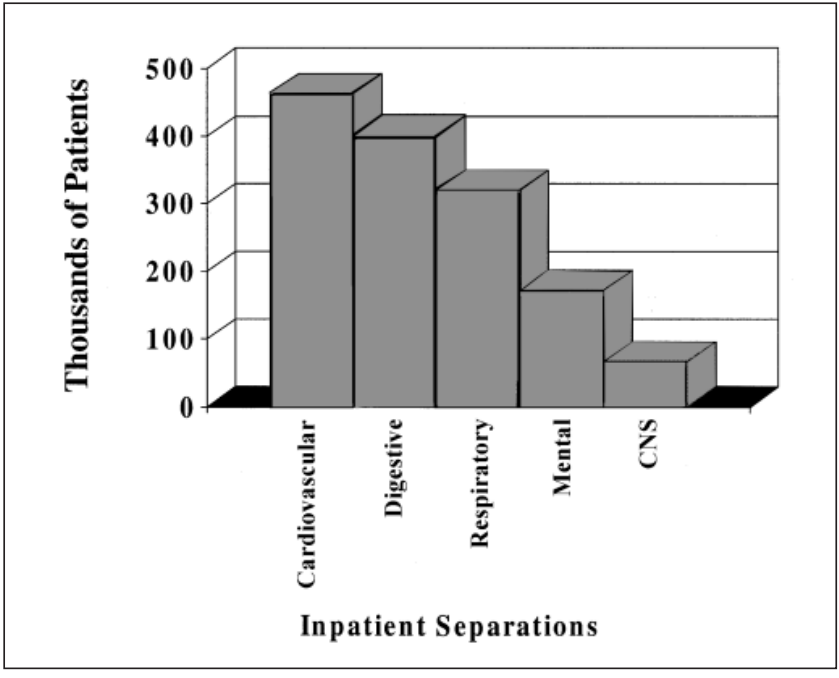

Figure 2) Inpatient separations (discharges) in Canada during 1997. Inpatient separations for digestive, nutritional and oral diseases ranks second in Canada. Digestive includes gastrointestinal, nutritional and oral health. CNS Central nervous system. Data from reference 1

TABLE 2

Annual value of lost productivity due to short term disability by diagnostic category (Canada, 1993)

\begin{tabular}{lrc}
\hline Diagnostic category & Cost $\times \mathbf{\$ 1 0 0 0}$ & Percentage of total \\
\hline Respiratory diseases & $4,357,224$ & 24.8 \\
Injuries & $3,242,540$ & 18.5 \\
Musculoskeletal diseases & $1,753,851$ & 10.0 \\
Digestive diseases & $1,147,567$ & 6.5 \\
Nervous system and sense organ & 896,058 & 5.1 \\
$\quad$ diseases & & \\
Mental disorders & 811,508 & 5.1 \\
Pregnancy & 681,726 & 3.9 \\
Genitourinary diseases & 521,505 & 3.0 \\
Cardiovascular diseases & 425,348 & 2.4 \\
Infectious and parasitic diseases & 381,704 & 2.2 \\
Cancer & 251,205 & 1.4 \\
Skin and related diseases & 108,808 & 0.6 \\
Blood and related diseases & 86,926 & 0.5 \\
Perinatal conditions & 66,696 & 0.4 \\
III-defined conditions & $1,819,170$ & 10.4 \\
Other diagnostic categories & 996,937 & 5.7 \\
Total & $17,548,772$ & 100 \\
\hline
\end{tabular}

eases (including the common cold), injuries and musculoskeletal diseases (Table 2). These numbers, of course, do not include loss of productivity due to nutritional and oral-dental disorders, for which Canadian data are not available.

\section{REFERENCES}

1. Fraser RD, Spasoff RA, Prime MG. Towards the establishment of health research priorities: An estimate of the economic burden of ill health. Toronto: Ontario Council of Health, 1976.

2. Moore R, Mao Y, Zhang J, Clarke K. Economic burden of illness in Canada, 1993. Ottawa: Health Protection Branch, Laboratory Centre for Disease Control, 1997. 


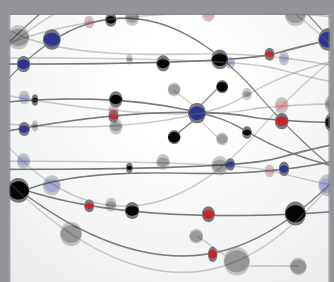

The Scientific World Journal
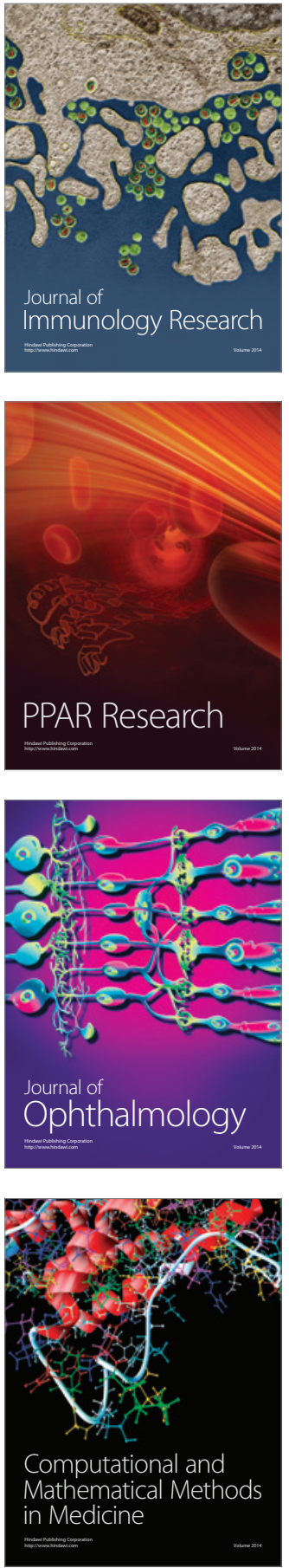

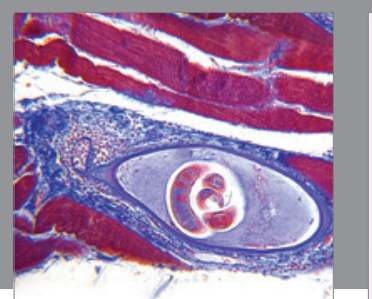

Gastroenterology Research and Practice

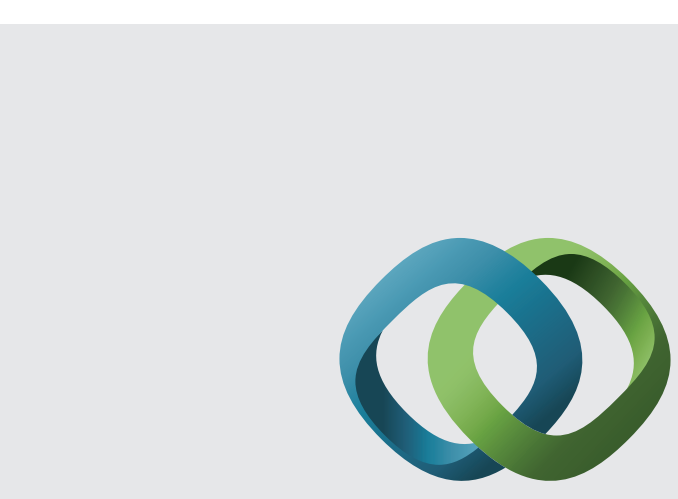

\section{Hindawi}

Submit your manuscripts at

http://www.hindawi.com
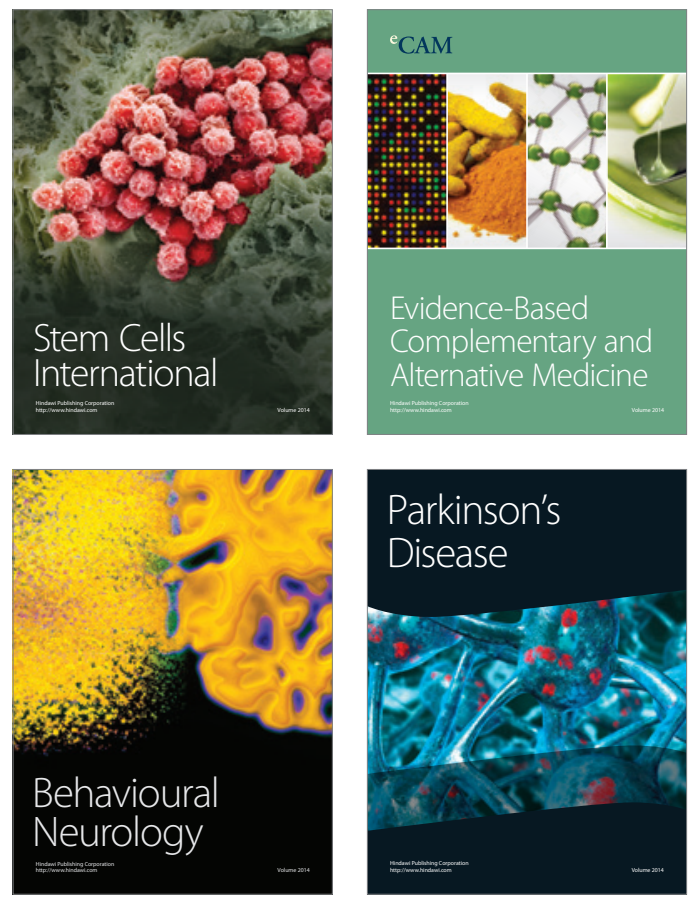
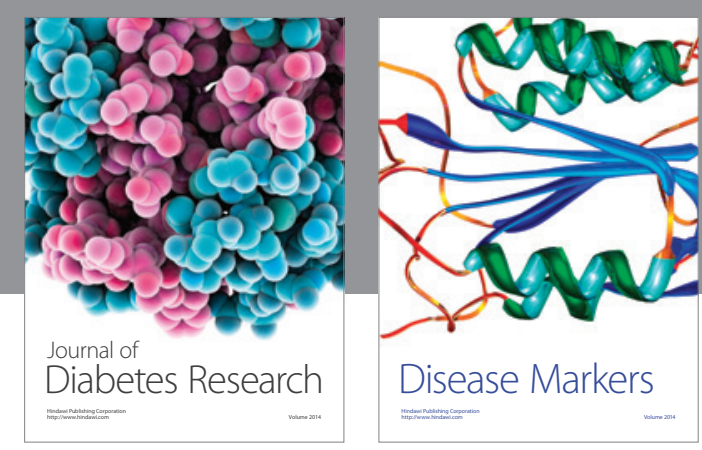

Disease Markers
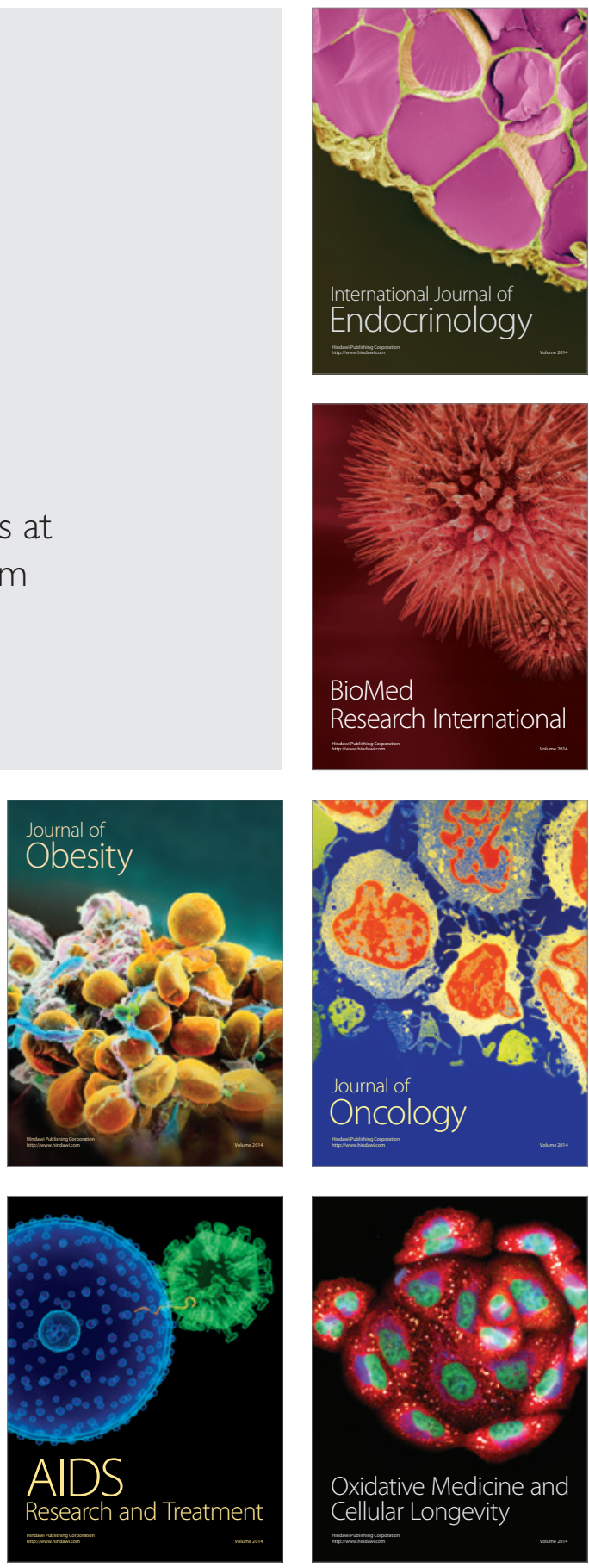